\title{
Morphological research on Compact University Campus: Taking the case of Dushu Lake Higher Education Town
}

\author{
Yezi Dai
}

\begin{abstract}
As China's future higher education will go towards the direction of industrialization, diversification and openness, and correspondingly, the objectives of university campus space will inevitably point at compactness, intensification and humanity. Taking Suzhou Dushu Lake Higher Education Town for example, the essay explored a morphological pattern of compact university campus which is suitable for the future development of university by analyzing the characteristics of its teaching model, functional features, transportation form and boundary space.
\end{abstract}

Index Terms - Compact, campus, morphology, Suzhou Dushu Lake Higher Education Town.

\section{INTRODUCTION}

Suzhou Dushu Lake Higher Education Town, hereinafter referred to as SDLHET, is located to the east coast of Dushu Lake of Suzhou Industrial Park which covering about 11 square kilometers.(Fig. 1) Research institutes or graduate schools of 22 higher education institutes including People's University, Nanjing University, Hong Kong University and other institutions have been settled here. On one hand, the town provided the platform which was set up by the government for universities that are then responsible for education, market-oriented, logistics urbanization, management modernization. on the other hand, it learns from the successful experience of foreign higher education town by means of infrastructure sharing, mutual opening and combination of campus with the aid of urban planning. Therefore, from space analyzing of the core SDLHET area we can find out the morphological characteristics of a compact campus space in aspects of overall land size, quantities of institutes, functions and transport. (Fig. 2)

\section{LAND FORMS}

From the features of land use and the comparison of land use among main higher education parks in Yangtze River Delta region (Table I), the overall and individual area of SDLHET is far smaller than other cases under the terms of equivalent quantities of universities. (Fig. 3) The primary reason is the different school running models. Besides the

Manuscript received December 23, 2017; revised May 12, 2018. This work was supported by the science and technology programs of Ministry of Housing and Urban-Rural Development of PRC under Grant 2016-R2-011, and the sponsorship of Jiangsu Overseas Visiting Scholar Program for University Prominent Young \& Middle-aged Teachers and Presidents.

Yezi Dai is with Golden Mantis School of Architecture, Soochow University, JS 215123 P.R.China (e-mail: daiyz@suda.edu.cn). local university - Dushu Lake campus of Soochow university, the vast majority of universities in the town are institutions of famous domestic universities, that is, their branch campus. The remote education model which is often only in a certain type of discipline or stage of education, such as graduate education, is different from traditional comprehensive schools. It emphasizes pertinence and characteristics in teaching and takes high efficiency and economy as its important indicator in operation, in order to highlight the features of differential teaching characteristics and utilization of intensive resources under the trend of industrialization of education, which was mentioned at the beginning of the essay. All of above elements lay the foundation for the realization of compact campus space [1].

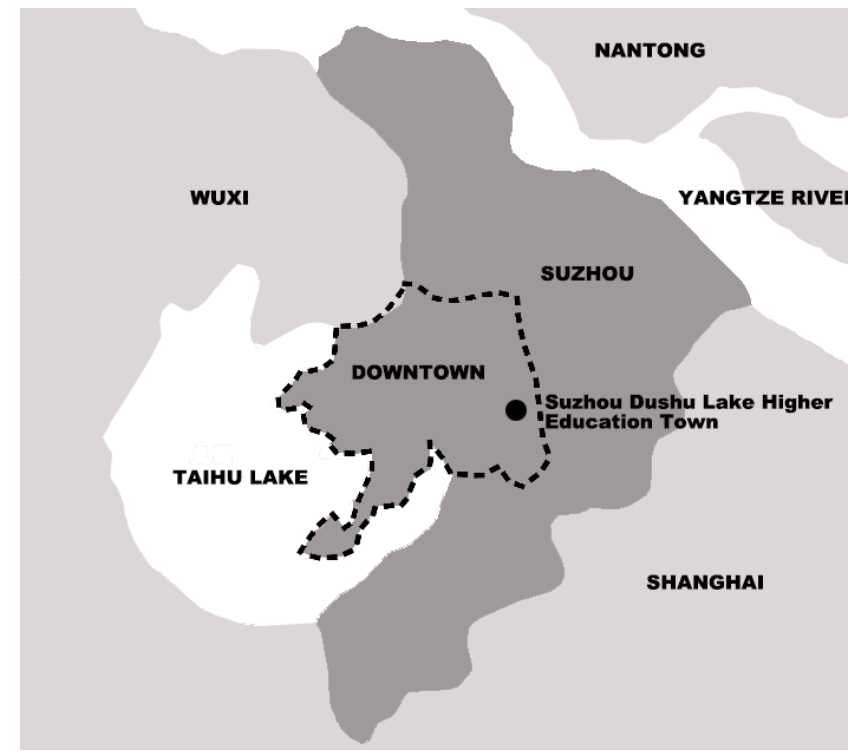

Fig. 1. Location schematic diagram.

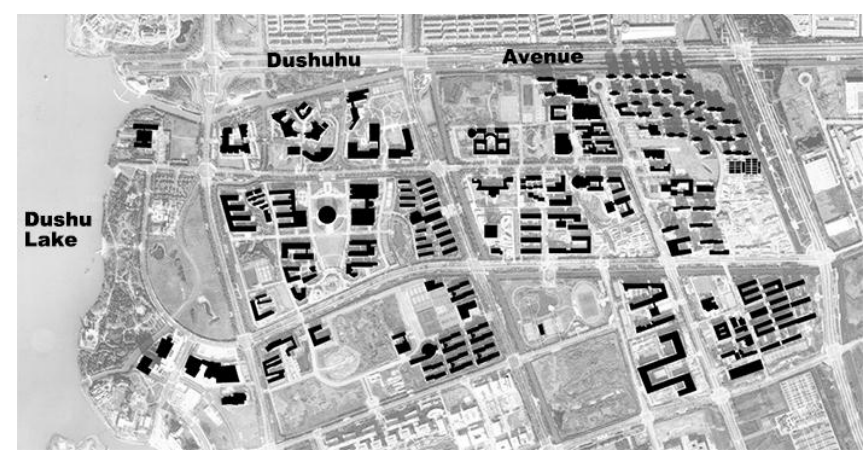

Fig. 2. Building distribution of core area.

From table I and Fig. 3, it can be easily found that the presence of the local university, Dushu Lake Campus of Soochow University, which holds traditional mode of operation has significantly affected the average area of 
SDLHET. It is clear that aforementioned flexible educational model can effectively avoid the waste of land resources caused by large and comprehensive universities. Furthermore, social management patterns can integrate public teaching, living services and other functions among different universities, and they further reinforce the trend of compact and increase efficiency of land bearing.

TABLE I: LAND STATISTICS OF THE MAIN HIGHER EDUCATION TOWN IN YANGTZE RIVER DELTA

\begin{tabular}{|l|l|l|}
\hline & Quantity of School & $\begin{array}{l}\text { Average area of } \\
\text { School(ha) }\end{array}$ \\
\hline $\begin{array}{l}\text { Core Area of Suzhou } \\
\text { Dushu Lake Higher } \\
\text { Education Town }\end{array}$ & $9(8)$ & $15.5(7.9)$ \\
\hline $\begin{array}{l}\text { Shanghai Songjiang } \\
\text { Higher Education Town }\end{array}$ & 7 & 48.2 \\
\hline $\begin{array}{l}\text { Nanjing Xianlin Higher } \\
\text { Education Park }\end{array}$ & 12 & 61.2 \\
\hline $\begin{array}{l}\text { Hangzhou Xiasha Higher } \\
\text { Education Park }\end{array}$ & 14 & 34.7 \\
\hline
\end{tabular}

Note: Data of area comes from Google map, and figures in brackets are not including that of Dushu Lake Campus of Suzhou University

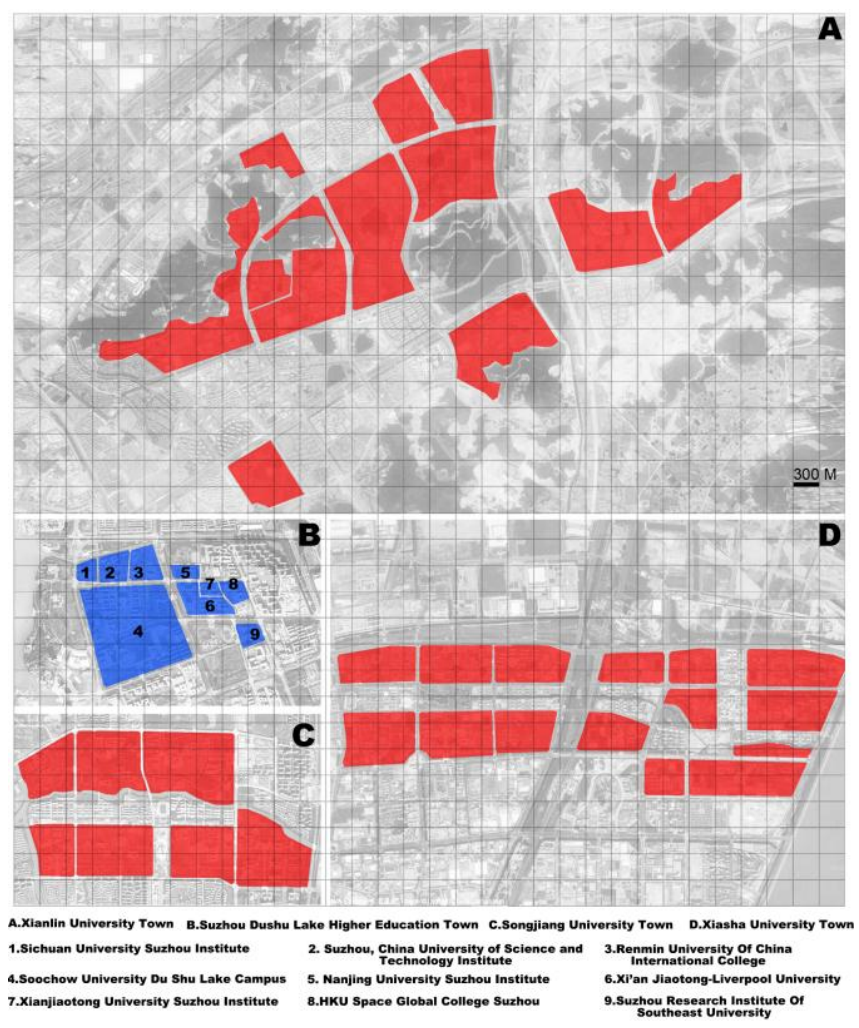

Fig. 3. Proportional space comparison chart of main higher education town of Yangtze river delta.

\section{FUNCTION CHARACTERISTIC}

As to the function, the most significant point is reflected in the general functional partition of Higher Education Town. Library and information center, fitness facility, shopping and entertainment area are separated from traditional university and are integrated because of the change of management which reduces the size of campus even more. (Fig. 4) The advantage of this separation results in not only the compactness and efficiency of internal campus space but also the reduction of unnecessary traffic and interference. What's more, the integrated functions obtain certain economies of scale and thus cut down the costs of management. From the user's perspective, the integration of public resources is beneficial to communication and discussion between teachers and students from different disciplines and institutes [2]. At the same time, they are also opened to the public with an open attitude to the society, and change the impression of superiority that the university has given to the general public. While creating economic benefits, SDLHET also consolidate other functions which are unrelated to the core teaching functions of daily university operations and introduces socialized management. This is not only the development trend of similar education town throughout the world, but also an effective way for the cities that are confronting the shortages of higher education resources to resolve the concerns of settled universities and attract high-quality education resources.

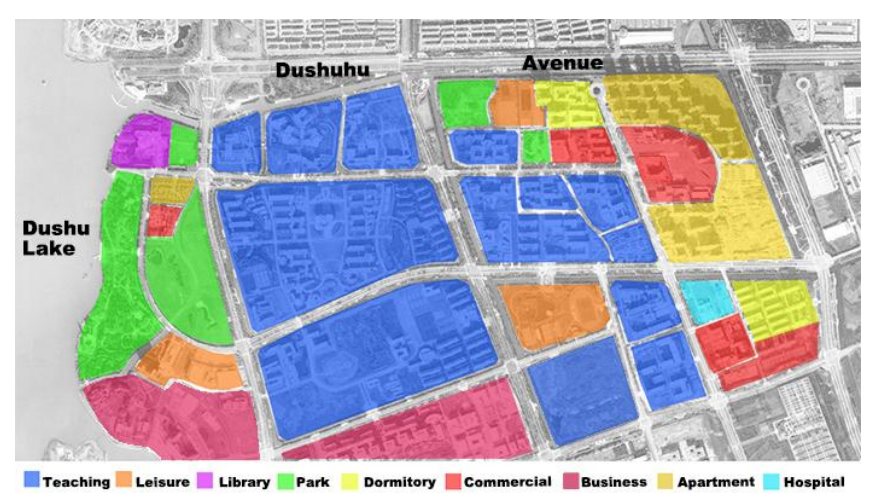

Fig. 4. Functional Analysis Diagram of Core Area

The new feature on function is also reflected at the micro level-spatial configuration of campus internal function. Teaching pattern of remote education has advantages of conciseness and efficiency, which provide favourable condition for the complex use of interior space of teaching buildings [3]. For example, Xi'an Jiaotong-Liverpool University takes a comprehensive teaching building and its front square to carry out the spatial sequence of campus-front space. This complex building which is a mixture of teaching, office, reporting, public service and many other functions, is the main place of teachers and students' daily work, study and live. The vertical overlapping spatial mode which centers around teaching function, has broken through horizontal spatial patterns of the previous single-functional campus building. It holds the virtues of high intensivism and efficiency in space utilization, as well as the merits of humanity and openness of the times highlighted during the process of use [4].

\section{Spatial Scales}

In the level of spatial scale, excessive pursuit of land size from traditional university has made the huge single-functional group of campus lies in the urban space and cuts off the organic links between adjacent regions of city and the transportations within. The uncontrolled campus dimension result in a uncoordinated relationship with the urban fabric, and was contrary to the open and inclusive 
education philosophy of the new generation universities. But in the compact campus, the relatively intensive land size is expected to change the morphology with huge scale and closed space of traditional university. By analyzing figure-ground relation of the core area of SDLHET, it can been seen that the block scale of campus separated by municipal road in the town district are similar to the surrounding living streets, which greatly improves the city's spatial quality, enriches the urban landscape, and shapes a stark contrast to the nearby local university-Dushu Lake Campus of Soochow University [5]. It is also necessary to point out that through the guide and assistance of the management and planning, universities of SDLHET spontaneously connect internal campus roads with urban roads which allows traffic outside freely pass through campus space, and further digest the scale and size of campuses.

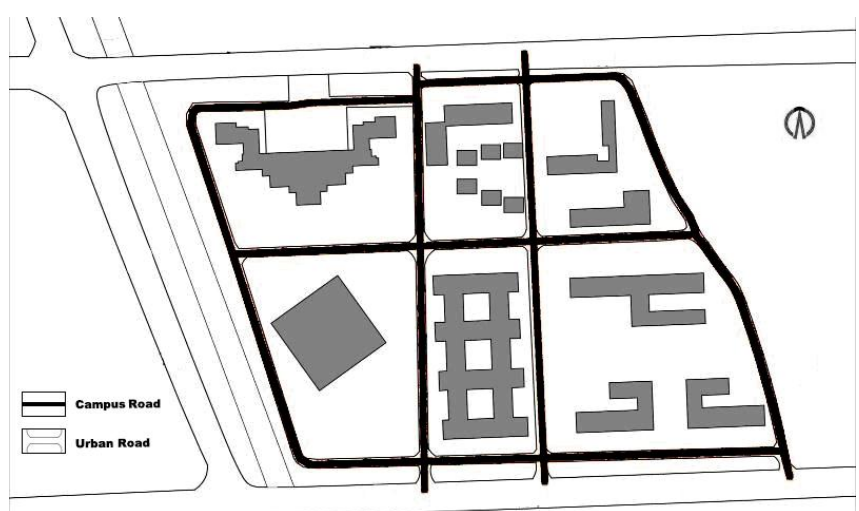

Fig. 5. Traffic Analysis of Xi'an Jiaotong-Liverpool University.

Meanwhile, the well maintained environment of campuses could be shared by city which perfectly embodies pluralistic and open education ideas of contemporary university and human-oriented cultural connotations. (Fig. 5)

\section{CAMPus Boundary SPACE}

From perspective of campus boundary space, it is the transition zone between city and university which plays the role in the definition of campus area. The boundary space brings another characteristics of compact campus. Also take Xi'an Jiaotong-Liverpool University for example, as its campus buildings which directly front the urban space are playing an important part in enclosing city streets, hence the street space and urban activities are taken into considerations in architectural design and planning of the exterior space [6]. This space model of "city motor vehicle lanes - sidewalks greenbelt - parking zone - auxiliary road - greenbelt pedestrian area - ground floor retail shop" takes an effective part in the filtration of multi layers composed of transportation, pedestrian stream, environment and ambiance during the spatial transition from urban space to campus's side. All of the elements above are simultaneously shared by a variety of people and meet there needs. The auxiliary road not only functions as the campus ring road of transporting and firefighting, but also as a necessary complement part to the urban traffic. The parking lots outside auxiliary roads on both sides could also be provide for university faculty and general public. Accommodating many functions of catering, bank, supermarket and other service relating closely to daily life, the shops along the street on the ground floor of teaching buildings provide services for campus, community and city, while at the mean time they also activate street atmosphere and produce a pleasant, comfortable urban space. The ambiguity in function and space can fundamentally account for the maintenance of streets vitality and creation of livable cities [7]. A similar situation also appears in the manipulation of campus boundary space of International College of Renmin University of China. (Fig. 6-8).

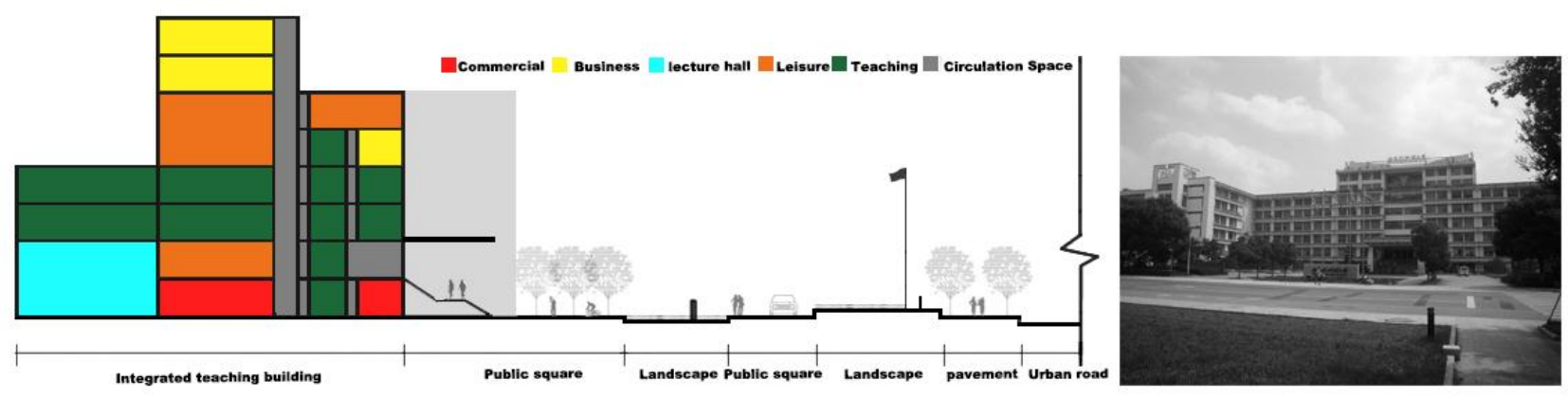

Fig. 6. Profile of the Comprehensive Building and Its Front Square of Xi'an Jiaotong Liverpool University

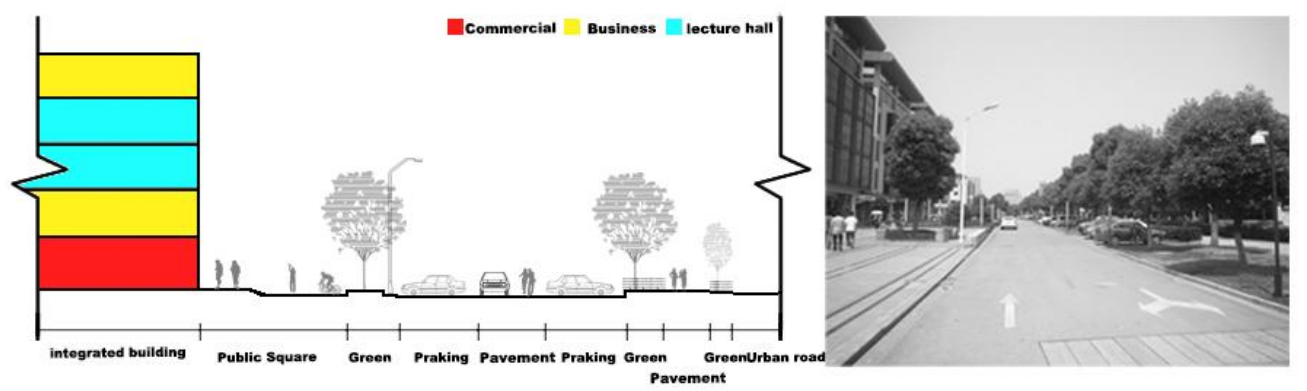

Fig. 7. Profile of Teaching Building down the Street of Xi'an Jiaotong-Liverpool University 


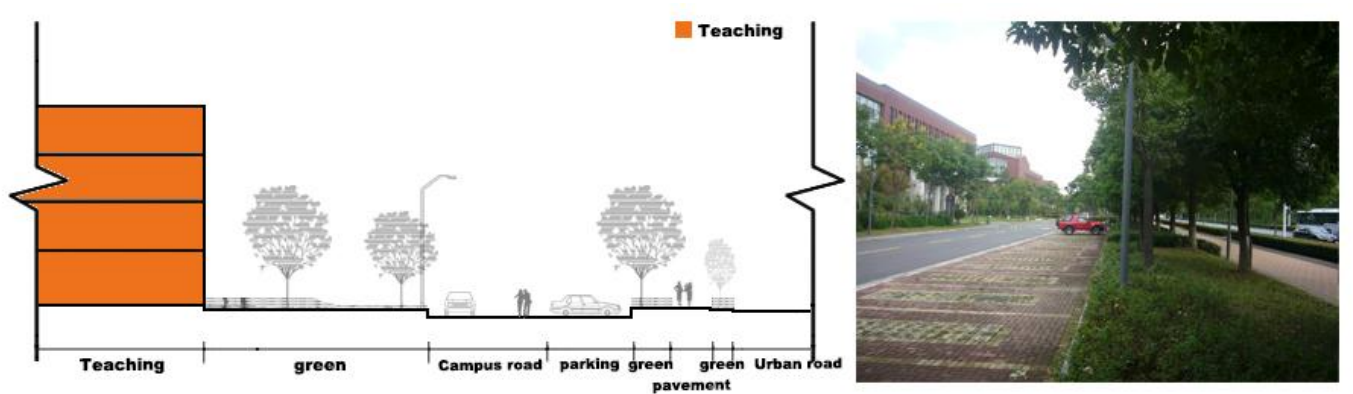

Fig. 8. Profile of Teaching Building down the Street of International College of People's University.

\section{CONCLUSION}

Through the above analysis, it can be seen that the compact university space has realized extraction and integration of campus life and services function, as well as the cross and compound of internal teaching function. It also leads to compact and intensive land size and campus space, and brings about improvement of urban spatial scale and enhancement of urban space quality. This conforms to the open and humanism of future universities and the trend of humane development of urban space which is expected to become the next developing direction of China's university campus and its surrounding urban forms.

\section{REFERENCES}

[1] W. Jianguo, Creation and Enhancement of Campus Culture, Nanjing, Southeast University Press, 2009

[2] T. Huijun, Overall Design of Campus - Planning • Landscape • Architecture, Beijing, China Construction Industry Press, 2007

[3] D. Newman, X. Li, and S. S. Translate, College and University Buildings, Beijing, China Construction Industry Press, 2007

[4] H. Jingtang, Planning and Design of Contemporary Campus, Beijing, China Construction Industry Press, 2006
[5] L. Re, "On communication space shaping of University Campus Take Taiwan Chaoyang technology university for example, "Jiangsu Architecture, vol. 3, pp. 4-6, 2011.

[6] Z. Hanqing, "Social Space Strategy of Universities, "City Planning, vol, 7, pp.57-59, 2010.

[7] D. Xiaodan, M. Fanjin, and C. Hui, "Analysis of spatial form of university boundary," Shanxi Architecture, vol. 3, pp. 13-14, 2010.

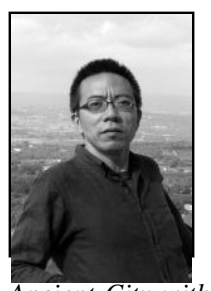

Yezi Dai is a Ph.D. in architectural design and theory, School of Architecture, Southeast University, Nanjing, China, 2010.

He is now the deputy dean and associate professor of department of Architecture, Soochow University of Suzhou from 2010. Historical Buildings at Soochow University (Suzhou,: Soochow University Press. 2014). Study of the Related Issues of Suzhou Ancient City with Modern Updating (Blue Book of Suzhou 2012-The Development Report of China's Suzhou. Suzhou, Jiangsu Province: Guwuxuan Publishing House. 2013, pp. 287-295). Current research interests are modern architectural and urban morphology and morphological transition of traditional Chinese city. 